\title{
J
}

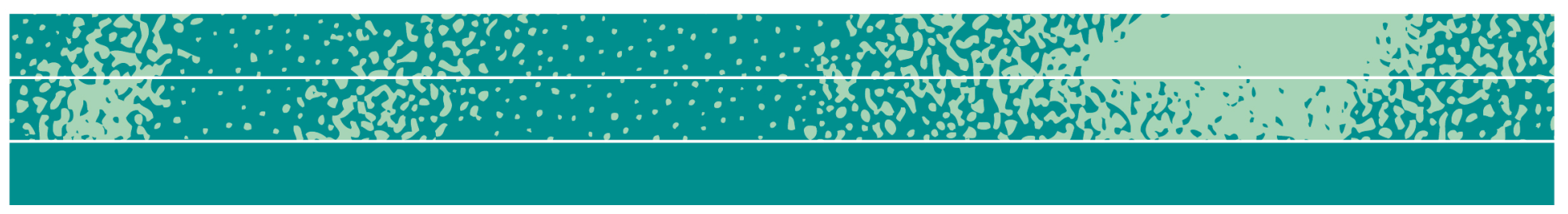

\section{Afterword: Questions of an Anthropology of and Anthropology for Business}

\author{
Melissa Cefkin
}

Concerns about positioning sit at the very heart of anthropology. While a matter of seemingly heightened concern recently, the significance of positioning dates back to the very origins of the discipline. Malinowski's time in the Trobriand Islands and Boas' travels to the Baffin Islands solidified the shift from the arm-chair analysis of the late 1800 's to active empirical investigation in the field. It is worth pausing to note that these developments happened almost accidently, as if each man tripped over experiences and observations that encouraged them to see things differently, with Malinowski's long stay in the Trobriands as an exile from war and Boas' travels as a physicist and geographer. Boas' case also reminds us, lest we forget, that other sciences go into the field for research as well. He went as a scientist to analyze the colors of seawater. His investigation turned specifically anthropological when he found that local people described numerous and varied colors from what he saw. It was not just being there, but being there and seeing things differently (or really, listening to things differently) that matters to anthropology.

Where we stand and from where we listen and speak matters.

There are at least three things at stake in these questionings of positioning. One is the positioning of the anthropologist herself. Where is she, how did she get there and why is she there? A second is the positioning of the actions the anthropologist takes to produce knowledge
Page 1 of 3

JBA 6(1): 121-123

Spring 2017

(C) The Author(s) 2017

ISSN 2245-4217

www.cbs.dk/jba 
about the subject at hand. Is the looking honest looking? Is it in the right places and at the right things? Is it enough and does it build on others' prior thoughts? (Or, put another way, is the data valid and the analysis theoretically informed?) And a third is the positioning of the discipline of anthropology vis-à-vis other domains of knowledge and practice. If we aren't a professional occupation dealing in practical effects, on the one hand, and we don't drive towards universal laws on the other, what do we deal in?

The anthropologist often finds herself needing to manage her positionality across all three of these stances at the same time, tacking back and forth between the role she is playing and the validity of the knowledge she produces, between the techniques she engages and their status in the worlds of both practice and science. And often she must grapple with simultaneous but nearly opposing gazes from two directions, from her interlocutors and co-participants in the field and from her fellow anthropologists 'back home' in the disciplinary halls of power.

Our practices do not always look that different from others we find inside, from others we encounter in the field. Anthropologists who work with marketing and brand professionals, for instance, may find themselves engaged in something of a semiotics smack-down, vying for who can render more insightful, more incisive or more useful meanings. Or we may have to contend with the fact that there is often little interest from our colleagues in the field, in the end, in how we do what we do, in our processes and approach, but only to the potential of the instrumentality of its effects.

For many of us who work "in", "with" and particularly "for" contemporary institutions of power such as business, worries about where we stand and from where we speak seem especially fraught. The interests and concerns we invest in when facing our fellow anthropologists and broader communities of scholars, and our interests and worries when facing those in the institutions and markets we hope to affect, are both profound and not necessarily the same. Today's anthropological work involves a double move: we consider not just the subject or site or problem at hand, whether it involves meat packing plants, sanitation workers, technical support or corporate strategists and change management leaders but also our own relationship to it. We project both forward and back to evaluate what we know, how we know what we know, and where it fits in the scheme of broader scholarly interests, knowledge and debates.

So perhaps it is no wonder that we repeatedly ask these questions about the positionality of our work, our knowledge, and our discipline. But who actually cares about the answer to this question? What kind of a question is it, really? In my experience, having spent decades, now, 
amongst scientists, strategists, managers and workers, the kind of selfreflexivity engendered by this set of questions is simply not typical of those who occupy the realms we work and reside in. It is by no means wholly absent-l've come to appreciate that people in the worlds we intersect in are certainly smart enough and thoughtful enough to ask them-but it's not a typical part of their professional practice, so why is it ours?

We have counted on both 'being there' and seeing and listening differently for our anthropological endeavor. The combining of ethnographic observation with questions of meaning and social and cultural forms are what make the discipline of anthropology. And yet we have also come to expect more. Embodied in the many and sustained inquiries into questions of positioning and the calls both for and against studying up, sideways, adjacent, with, in, for, and against are pushes for an accounting of ourselves and of our work, accountings of both our being there and of our ways of seeing. We are faced with questions not only of why we are there and what we are doing, but also (though often only subtlety and tangentially), is it enough and is it right? These questions are in part questions of epistemology, to be sure, and here we share with other sciences, both human and natural, in asking after the basis of our knowledge claims and the methods we use to arrive at them. But they are also questions of politics. Whose interests do we serve?

This reality should give pause to anyone continuing to imagine anthropology to be the swashbuckling discipline of adventure. These many entanglements suggest instead, for better or worse, a rather treacherous walk down an infinite hall of mirrors.

Melissa Cefkin (PhD Anthropology, Rice) leads a social science research team at the Nissan Research Center-Silicon Valley. She explores the potential of having autonomous vehicles as interactive agents in the world and works with technologists and designers to build socially acceptable and meaningful autonomous vehicles. Prior to Nissan, she was at IBM Research where her research focused on studies of work and organization. She also has experience in design and consulting, and was previously a Director of Advance Research and User Experience at Sapient Corporation, and a senior research scientist at the Institute for Research on Learning. Melissa served on the Board of Directors for the Ethnographic Praxis in Industry Conference (EPIC), as well as conference co-organizer. She is the editor of Ethnography and the Corporate Encounter (Berghahn Books 2009) and numerous other publications. A Fulbright award grantee, she enjoys frequent presentations at conferences, serves regularly on editorial and review boards, and has served a committee for the National Academies of Science and on a number of editorial boards. 